\title{
Entre civis e militares: o Estado, o mercado e a crise da ditadura nas páginas da revista Planejamento \& Desenvolvimento (1973- 1984)
}

Reinaldo Lindolfo Lohn*

\begin{abstract}
RESUMO
Por meio da análise da revista Planejamento \& Desenvolvimento ( $P \& D)$, publicação da Secretaria de Planejamento da Presidência da República durante a ditadura militar, este artigo objetiva discutir o papel de uma burocracia civil que pretendia modernizar o capitalismo brasileiro sem abrir mão da preponderância do Estado. Isso desencadeou debates no interior do regime em torno de demandas em favor do livre mercado localizadas tanto nos setores oposicionistas quanto nas bases sociais do governo autoritário. Sob uma perspectiva histórica, tais discussões podem contribuir para os debates contemporâneos acerca da própria condição do regime e das relações entre civis e militares, com implicações para a compreensão do processo de redemocratização.
\end{abstract}

Palavras-chave: Ditadura. Planejamento. Mercado.

\section{Between civil and military: the state, the market and the crisis of the dictatorship in the pages of Planejamento \& Desenvolvimento magazine (1973-1984)}

\begin{abstract}
This article aims to discuss the role of a civil bureaucracy that sought to modernize Brazilian capitalism without giving up the preponderance of state investments through the analysis of the Planejamento \& Desenvolvimento $(P \& D)$ magazine, an official publication of the Presidential Planning Secretariat during the Brazilian military dictatorship. The text focuses on the debates within the regime around demands for free market located in both the opposition sectors and the social bases of authoritarian government. From a historical perspective, such discussions may contribute to contemporary debates about the condition of the regime and the civil and military relations, with implications for understanding the process of redemocratization.
\end{abstract}

Keywords: Dictatorship. Planning. Market.

Artigo recebido em 30 jan. 2019

Aprovado em 14 abr. 2019

\footnotetext{
* Reinaldo Lindolfo Lohn é professor do Departamento e do Programa de Pós-Graduação em História da Universidade do Estado de Santa Catarina (UDESC). Doutor em História pela UFRGS. Este artigo resulta de projeto de pesquisa financiado pela UDESC e pela Fundação de Amparo à Pesquisa e Inovação do Estado de Santa Catarina (FAPESC). A documentação foi coletada pela então bolsista de Iniciação Científica Kelly Yshida. E-mail: reilohn@gmail.com.
} 


\section{Uma revista para um país com "pressa de crescer"}

O regime autoritário imposto ao Brasil por meio de um golpe civil-militar em 1964 atravessava seu auge no início da década de 1970, tanto em termos do funcionamento dos aparatos repressivos quanto na obtenção de respaldo junto a diferentes camadas sociais. Foi quando começou a circular, em 1973, a revista Planejamento \& Desenvolvimento (P\&D), periódico oficial do então Ministério do Planejamento e Coordenação Geral, órgão que no ano seguinte passou a ser denominado de Secretaria de Planejamento da Presidência da República (SEPLAN), quando se tornou ainda mais influente, durante o governo do general Ernesto Geisel. O informativo foi publicado até 1984 e veiculou boa parte das representações sociais às quais a ditadura pretendia associar-se, particularmente sua pretensa condição de regime desprovido de interesses políticos, afeito estritamente às necessidades técnicas e aos chamados interesses nacionais permanentes.

Este artigo visa analisar parte da trajetória da revista relacionando-a com o processo de abertura política no Brasil, desencadeado ainda durante a vigência do regime autoritário. Compreende-se aqui que tal processo sofreu os desdobramentos de tensões que envolviam setores da burocracia civil, situados em especial na área econômica, em torno da participação do Estado na condução das estratégias econômicas do país. Um episódio razoavelmente conhecido por meio de testemunhos e intérpretes é o que diz respeito aos debates em torno do pretenso aumento do tamanho e da importância do Estado na condução do processo produtivo durante o governo do general Ernesto Geisel (1974-1979). A análise do material proporcionado pela revista permite discutir o quanto aquelas discussões impactaram a relação entre esferas governamentais $e$ as camadas socio-profissionais que eram mobilizadas pelo ideário da ditadura, particularmente aquele que dizia respeito à transformação do país numa economia capitalista desenvolvida por meio da ação de setores com formação especializada e supostamente alheios à influência política.

Por outro lado, a defesa das liberdades políticas e sua ampliação para os chamados agentes econômicos, associando democracia e a chamada "economia de mercado", aproximava setores oposicionistas articulados no interior do Movimento Democrático Brasileiro (MDB) com grupos até então alinhados ao governo autoritário. Esta aproximação de interesses políticos e ideológicos entre políticos, burocratas civis e setores do empresariado industrial interessados na redução dos mecanismos de controle estatal sobre a economia teria desdobramentos na chamada "abertura", proposta pelos últimos presidentes militares. 
Um dos elementos que caracterizaram as negociações que levariam à abertura política envolvia a defesa do "livre mercado" por parte de uma nova articulação que envolveu segmentos políticos, empresariais e da grande imprensa, num momento de crise do Estado como investidor, o que punha em questão seu papel na definição das políticas públicas no país. Por meio da revista Planejamento \& Desenvolvimento, ou simplesmente $P \& D$, denominação preferida pelos editores da revista - e será assim reportada ao longo do texto - é possível discutir algumas das tensões que marcaram as relações políticas no interior do governo ditatorial e em seus liames com os setores sociais que o sustentavam na segunda metade da década de 1970. Portanto, não se trata de dar à revista uma centralidade que esta obviamente não possuiu, por não se tratar de um mecanismo de comunicação de massa. Mas seu direcionamento para um público específico, formado por profissionais de nível médio e superior ligado às áreas da administração pública e empresarial, permitirá compreender a amplitude de uma discussão que desafiava os próceres do regime autoritário: sua continuidade e institucionalização em meio à distensão política proposta então por Geisel.

A revista foi apresentada como espaço para discussão dos "problemas nacionais" com os "formadores de opinião". É possível compreender que este público era formado por um grupo considerado seleto de profissionais de nível superior das classes médias e do estrato mais alto da sociedade, em sua maioria civis, então sob a influência de iniciativas e realizações apresentadas como a concretização de um "milagre econômico", um dos temas de predileção do regime em suas estratégias de comunicação. Ao todo foram editados 89 números da revista, que procurava fugir do padrão de publicações oficiais, com matérias jornalísticas abrangentes e entrevistas, embora não tenha deixado de sucumbir em diversas oportunidades à linguagem burocrática. Desde o início de sua circulação, o periódico produziu uma narrativa segundo a qual o regime estaria comprometido com a transformação das estruturas sociais brasileiras por meio de um aparelho coordenador estatal com amplo alcance em relação aos problemas sociais, econômicos e culturais do país. Este artigo concentra-se na principal fase da revista, seus anos iniciais, entre 1973 e 1977, correspondendo a 55 edições, quando atingiu sua mais alta tiragem e foi diretamente influenciada pela gestão do ministro João Paulo dos Reis Velloso, principal articulador das respostas governamentais às críticas à intervenção estatal na economia, embora tenha sido necessário, para a melhor compreensão do documento, estender a investigação para todo o período de sua existência.

Apesar de pretender mostrarse como a realização de um sistema ordenado e hierárquico, capaz de reorganizar a sociedade brasileira em torno de um eixo vertical que consagrava a 
autoridade derivada da competência do saber (Fiorin, 1988, p. 32-33), a ditadura que se seguiu ao golpe não impediu a emergência de divisões e conflitos em suas tomadas de decisões. Neste aspecto, não é possível deixar de levar em conta a necessidade de considerar a revista como uma peça de interlocução entre as partes que se julgavam os setores mais destacados da burocracia civil da ditadura, principalmente aqueles ligados à área do planejamento econômico, daí que é importante considerar as características contraditórias de uma ditadura conduzida por militares sob a colaboração de civis. Os debates entre o grupo burocrático da SEPLAN, conduzido durante o governo Geisel (o "IV governo da Revolução") pelo ministro Reis Velloso e por segmentos empresariais e da grande imprensa - notórios apoiadores do regime - quando o planejamento centralizado $e$ a ação intervencionista do Estado passaram a ser questionados, são aqui interpretados como parte do processo que articulou forças políticas no âmbito das negociações que organizaram a chamada redemocratização do sistema político brasileiro.

Tomar a revista $P \& D$ como documentação histórica explorada para descortinar elementos desses debates tem como implicação inicial identificar os limites impostos à sua análise, cabendo reconhecer que se trata de uma publicação laudatória e homogênea, sem qualquer distanciamento em relação à ditadura. Sua circulação foi iniciada em um período em que os instrumentos de comunicação utilizados pelos governos militares ganharam uma forma mais consistente, no âmbito da atuação de estruturas profissionalizadas, como foi o caso da Assessoria Especial de Relações Públicas (AERP), as quais buscavam evitar aparecer como grandes órgãos de propaganda oficial - como o notório Departamento de Imprensa e Propaganda (DIP) durante a ditadura Vargas -, valendo-se da interação com a iniciativa privada e em diálogo com a publicidade, conforme apontado em trabalhos como os de Carlos Fico (Fico, 1997) e o estudo mais recente de Nina Schneider (Schneider, 2017). A revista pode ser abordada no interior de um conjunto de publicações oficiais que buscavam reunir os setores considerados mais sofisticados da burocracia estatal civil e de colaboradores intelectuais com vistas a dotar de legitimidade social as iniciativas e políticas impostas pela ditadura, além de procurar debater os temas tratados pela grande imprensa. Uma prática comum adotada pelos editores foi a de reproduzir de modo sintético os debates travados em jornais influentes que versavam sobre a política econômica, de maneira a favorecer o ponto de vista do governo.

A interpretação do material recolhido nas páginas da revista pode aproximar-se daquela realizada em diferentes estudos por Angela de Castro Gomes e relativos à revista Cultura Política, editada pelo DIP durante o Estado Novo, cuja pretensão envolvia uma política cultural na qual estivessem engajados diferentes setores intelectuais que "espelhassem" uma sociedade em 
mudança (Gomes, 1996). Há em $P \& D$, contudo, o interesse específico de demonstrar a capacidade dos órgãos técnicos estatais na condução de políticas capazes de motivar a iniciativa privada para o esforço nacional, reduzindo a importância da mobilização social, como fora o caso do Estado Novo, caracterizado por sua pretensão de seduzir as massas para um projeto de construção da nação e de uma nova cidadania por meio da apresentação do poder como um espetáculo com tempo e ritmo próprios (Capelato, 1998). O regime de 1964 procurou construir mecanismos de interação com a sociedade forjados segundo uma lógica de eficiência produtiva e ganhos materiais individuais. No caso de $P \& D$ os instrumentos de propaganda e persuasão são substituídos pela informação em moldes jornalísticos francamente dirigida para um público comprometido com o regime e engajado no esforço duradouro de sustentar a ditadura.

Em seu primeiro número, no mês de julho de 1973, a revista trouxe uma matéria de capa intitulada "Por que treinar os executivos?". No editorial, que durante toda a existência da publicação foi chamado de "Conversa com o leitor", defendia-se que o subdesenvolvimento não seria "apenas um conjunto de índices e taxas, mas uma postura mental". Uma nova atitude "psicológica" da população seria indispensável no momento em que o país alcançava "as mais altas taxas de crescimento". Nessa época foi lançado o "Programa de Treinamento de Executivos", tendo como alvos o apoio técnico e a formação de recursos humanos na área da Administração de Empresas, de modo a atingir a "modernização da empresa nacional" e a realização das metas do I Plano Nacional de Desenvolvimento (PND). A "mudança de mentalidade do empresariado" resultaria tanto da formação universitária quanto de ações voltadas para o interior das empresas. O país tinha pressa e não poderia "esperar 5 ou 10 anos pelas primeiras fornadas de bons administradores" (P\&D, jul. 1973, p. 22-25).

Nesta matéria estão expressos alguns aspectos do que se pode chamar de uma ordem empresarial, recorrendo ao trabalho clássico de René Dreifuss, para quem, sob a perspectiva de Gramsci, o golpe de 1964 significou a consolidação de um bloco de poder empresarial que, de francamente oligárquico, passou a ser influenciado pelo capital monopolista e multinacional a partir da década de 1950 e unificou diferentes setores da burguesia industrial brasileira aos tradicionais grupos organizados do latifúndio, colmatando a aliança vitoriosa com os militares (Dreifuss, 1981). Pela ação de diferentes iniciativas de organização - especialmente o Instituto de Pesquisas e Estudos Sociais (IPES) - o bloco empresarial, que havia sido reestruturado pela ascensão da produção industrial de bens de consumo duráveis associada ao ingresso de capital internacional, ganhou capacidade de integração e interlocução política ao longo dos anos que antecederam o golpe, tornandose uma "elite orgânica" materialmente capaz de ampliar as 
"perspectivas elitistas e consumistas das classes médias" e de fomentar "o temor às massas" quanto aos supostos riscos do comunismo. Esta ordem empresarial estará em discussão ao longo da publicação de $P \& D$, com a pretensão da SEPLAN em garantir-lhe uma unicidade e engajamento às políticas do regime. Portanto, a referência a "empresários" neste trabalho diz respeito a esta "ordem administrativa de inspiração empresarial e de segurança política" que envolvia o grande empresariado monopolista nacional e multinacional (Dreifuss, 1981, p. 103-105; 134; 230).

A revista tinha circulação dirigida e era remetida a órgãos públicos e empresas privadas, assim como a diferentes interessados em fazer parte de seu cadastro de assinantes gratuitos. Foi criada sob a direção de Arivaldo Silveira Fontes, militar integrante do Instituto Histórico e Geográfico Brasileiro e que atuara no magistério em instituições de ensino vinculadas ao Exército, com a editoria de Pery de Araújo Cotta, jornalista com atuação na grande imprensa. As matérias, em geral, não eram assinadas, o que dá conta que a equipe, toda ela vinculada à SEPLAN, assumia controle sobre o conteúdo, ademais quase inteiramente produzido nos corredores ministeriais em Brasília. Apresentavase no formato de 21 por 27 centímetros e na grande maioria das edições circulou com 66 páginas. As capas costumavam apresentar trabalhos gráficos bem elaborados e sempre em cores. Sua tiragem inicial foi de 20 mil exemplares, chegando a 36 mil mensais desde maio de 1974 até outubro de 1977, quando começou a cair, estabilizandose em 25 mil.

Lançada no período mais agudo da repressão política, a revista acentuava o entusiasmo oficial com o "aumento rápido da produtividade econômica da sociedade". O Brasil, como nação jovem, tinha "pressa de crescer" e de aumentar a produtividade do trabalho para "abreviar o tempo, muitas vezes terrivelmente longo, que o desenvolvimento econômico exige habitualmente". Para tanto, o regime contava com os leitores da revista, um "grupo selecionado de líderes de opinião de todo o país" ( $P \& D$, jul. 1973, p. 3). Passado o primeiro decênio da "revolução", era necessário reativar seus "ideais" $e$, principalmente, as bases que deram sustentação ao golpe de Estado, agora sob a roupagem da eficiência para levar o país a tornar-se uma potência capitalista organizada em uma institucionalidade nova, criada pelo regime e aceita pela sociedade. Neste aspecto, organismos como o Instituto de Planejamento Econômico e Social - posteriormente de Pesquisa Econômica Aplicada (IPEA) -, deveriam assumir um papel diferente daquele desempenhado pelo IPES em 1964, articulando novas práticas administrativas voltadas para renovar as elites empresariais. Mas o ambiente da década de 1970 inspiraria diferentes alternativas, entre as quais aquelas sugeridas por uma virada neoliberal que tenderá a surpreender o próprio regime. 


\section{Opiniões formadas}

A partir de dezembro de 1974, $P \& D$ passou a contar com uma seção de cartas de leitores com a qual é possível formar um breve perfil de parte do público da revista a partir dos vínculos profissionais informados. Embora não haja aqui a intenção de uma análise exaustiva e sociológica do público da revista, cabe buscar uma tênue imagem dos setores sociais que eram alcançados pela publicação e nos quais o regime buscava extrair legitimidade social. Nos anos em que sua periodicidade foi mensal, entre 1974 e 1979, a revista publicou em torno de 400 cartas. Neste intervalo de tempo, a proporção de mulheres missivistas ficou pouco abaixo de $20 \%$, embora o percentual tenha melhorado lenta e continuamente ao longo do período. Em cerca de dois terços das cartas é possível identificar as atividades de leitores ou leitoras, sendo que as mais comuns eram: docentes do ensino superior (com uma grande proporção das áreas de Administração, Economia e Estudos de Problemas Brasileiros), dirigentes de órgãos públicos, executivos e empresários, estudantes universitários majoritariamente da área de Administração de Empresas, economistas, engenheiros, administradores, profissionais liberais de diferentes áreas e, em menor número, docentes de ensino médio, religiosos, médicos, militares, políticos, bibliotecários, contabilistas, jornalistas, funcionários públicos, agricultores, advogados e bancários. As correspondências tendiam a reforçar o apoio às decisões do regime, afirmando a crença nas promessas de transformação do país em uma potência moderna, como se o país estivesse vivendo seus "anos de ouro" (Cordeiro, 2009, p. 91). Este perfil, embora deva-se atentar para as possíveis distorções, como a presença de estudantes, é revelador da presença, em termos profissionais, de setores de uma "elite gerencial" beneficiária de uma ascensão social advinda da criação de postos de trabalho com "status ocupacional" elevado, o que acentuava as desigualdades sociais (Luna $e$ Klein, 2014, p. 75-80).

É possível localizar os leitores de $P \& D$ majoritariamente entre a classe média alta e as elites, tomadas como o estrato mais alto da estrutura de classes do país. A soma destes dois segmentos formava então um contingente que reunia cerca de $5 \%$ da população economicamente ativa, que girava em torno de 30 milhões de pessoas. A revista dirigiase, inicialmente, para um público potencial que pouco alcançava 1,5 milhão de pessoas em meados da década de 1970 , formado por famílias que contavam entre seus integrantes com profissionais de nível universitário. Estes setores conseguiam então rendimentos calculados que partiam de aproximadamente 10 salários mínimos mensais (o que equivaleria a cerca de 3.500 dólares atuais ou 10 mil reais), podendo ser 
obviamente muito mais altos no estrato superior. Este público tornouse mais diverso com o passar do tempo, pois as cartas e o próprio aumento da circulação mostram que a revista passou a alcançar profissionais especializados com rendimentos inferiores, como técnicos do setor privado e trabalhadores de escritórios e estudantes universitários da área de Administração, situados na classe média, que alcançavam um contingente de $13 \%$ população economicamente ativa ou cerca de 3,5 milhões de pessoas diretamente engajadas no processo produtivo (Pastore, 1976, p. 563567). Na diversidade de ocupações é possível identificar a prevalência, quanto à estratificação social, de uma classe média de "colarinhos brancos", empregada em funções especializadas dos setores público e privado e que, além de dispor de altos rendimentos, ganhou projeção e influência social nas modernas sociedades capitalistas após a Segunda Guerra Mundial (Mills, 1979, p. 360$371)$.

O conjunto de percepções e imagens acerca da sociedade brasileira mobilizado pela revista articulava a interação política entre Estado, classes médias urbanas $e$ as classes dominantes $e$ dirigentes brasileiras, pretensamente liberais, cujo projeto social fora imposto em 1964 pelos militares. Nesse misto de influências, o regime impôs-se pela força, mas também pelo franco apoio dos segmentos sociais compostos pela burocracia civil especializada e das elites dirigentes e empresariais. Para os fins desta discussão, é importante considerar que apesar de garantir que a industrialização e o desenvolvimentismo estivessem no centro de suas investidas sobre o conjunto da economia, o regime mantinhase também sob a influência do pensamento liberalconservador brasileiro que questionava a industrialização como panaceia. Alimentados pelos confrontos com o varguismo, oficiais militares haviam se aproximado de arautos do liberalismo conservador (Carvalho, 1999, p. 73-80). A acomodação entre autoritarismo, conservadorismo social, desenvolvimentismo e liberalismo levaria a rearranjos constantes nas relações políticas no interior da estrutura de poder e a tensões que afloraram na segunda metade da década de 1970. A junção ambígua de elementos políticos diversos expressouse ao longo do tempo na forma de uma "utopia autoritária" (Fico, 1997, p. 118), pautada na pretensa superioridade dos militares sobre os civis e que se alimentava de um elitismo que vicejava nos diversos âmbitos da administração pública $e$ das camadas médias e altas, bem como na tentativa de despolitizar a relação entre Estado $e$ sociedade.

À frente do planejamento governamental e em contato direto com a Presidência da República, João Paulo dos Reis Velloso estava em meio à sua longeva gestão que se iniciara sob o comando do general Emílio Médici. Economista com densa formação católica, manteve relações com a democracia cristã e com personagens como Plínio Salgado após 1945. Depois de atuar 
como assessor parlamentar do deputado Jorge Lacerda e de exercer outros cargos públicos, fez carreira no Banco do Brasil. Reis Velloso era integrante orgânico na alta burocracia da área econômica brasileira, quase toda com formação no exterior, especialmente nos Estados Unidos, em seu caso na Universidade de Yale, onde recebeu a influência de James Tobin, que fora conselheiro econômico de John Kennedy e era um intérprete liberal do keynesianismo e um dos formuladores da chamada síntese neoclássica. Embora também mantivesse diálogo frequente com as posturas desenvolvimentistas da Comissão Econômica para a América Latina (CEPAL) e com economistas estruturalistas, ao assumir o Ministério do Planejamento, depois transformado em SEPLAN, Reis Velloso era um ativo colaborador do regime desde seu início, quando foi responsável pela fundação do atual IPEA a convite de Roberto Campos (Castro e D'Araújo, 2004, p. $34 ; 101 ; 193)$.

Sua própria trajetória ilustra uma burocracia civil estatal que se pretendia capaz de dar forma ao aparelho de Estado brasileiro a partir da capacidade técnica adquirida pela formação profissional especializada. Na esteira da interpretação de Claus Offe, é possível destacar que se tratava da defesa da interação entre burocracia estatal e empresa capitalista, no sentido de que ao Estado e suas esferas burocráticas cumpre a efetivação do capitalismo, mesmo que eventualmente em desacordo com os próprios capitalistas. Para o autor, "a organização burocrática estatal permite ajustar de forma flexível as medidas político-sociais às exigências da economia de mercado" (Offe, 1984, p. 30; 145). Sob este prisma, o Estado não aparece como mera instância reprodutora de interesses externos isolados de capitalistas, mas como um aparato capaz de selecionar aquelas políticas que satisfaçam de modo abrangente o desenvolvimento do capitalismo em geral. Percebe-se que este trabalho de seleção envolve conflitos em torno de quais são os elementos de se expressar em um determinado momento histórico os interesses das classes dominantes. A tentativa de adquirir uma autonomia relativa e assim se portar constituiu um foco de confrontos que abriu ao longo da década de 1970 um intenso debate entre os setores do grande empresariado industrial e a burocracia estatal.

\section{A crise e a nova lógica liberal: manda quem pode}

Logo no segundo ano de circulação de $P \& D$, o ambiente político da ditadura apresentou alterações que teriam impactos significativos no período subsequente. Em 1974, o general Geisel, ao acentuar a necessidade da promoção de uma "eficiente motivação política do povo brasileiro", frisou que não aceitaria "pressões indevidas" que acelerassem "o processo de lenta, gradual e 
segura distensão, tal como se requer". ${ }^{2}$ Desde o ano anterior, integrantes do regime mantinham interlocuções que procuravam definir o que seria uma estratégia gradualista de descompressão, a partir de um estudo de Samuel Huntington que circulou em ambientes acadêmicos e políticos, com vistas à institucionalização controlada de um sistema político em colaboração com a oposição consentida do MDB (Skidmore, 1990, p. 165-166). O sistema partidário imposto dava ao regime a condição de mover-se segundo uma "lógica liberal" enquanto atuava de modo autoritário (Trindade, 1985, p. 66-72), com a manutenção limitada de instituições pretensamente representativas da sociedade, especialmente o parlamento, o judiciário e a imprensa, as quais funcionaram mesmo sob a vigência do Ato Institucional Número 5 (AI-5), imposto em 1968.

A fala do general-presidente reconhecia a interlocução com os setores políticos por meio da imprensa e da opinião pública. Isso tornou-se ainda mais importante após o governo sofrer uma expressiva derrota eleitoral nas eleições parlamentares de novembro de 1974. O governo autoritário tratava de buscar apoios no círculo dos que considerava "formadores de opinião" (P\&D, jun. 1975, p. 3). Nesta mesma época, a chamada Crise do Petróleo afetou um crescimento econômico acelerado e dependente de poupança externa e de investimentos públicos. Os aumentos dos preços internacionais do petróleo eram anunciados em toda a imprensa desde o final do ano anterior, ${ }^{3}$ mas em 1974 , ao menos nas páginas de $P \& D$, não suscitavam maiores preocupações e a discussão foi contornada. Apenas em meados do ano é que a revista se referiu ao problema das "importações de petróleo" e da "crise de energia", ao reproduzir uma conferência de João Paulo dos Reis Velloso na qual o ministro definia 1974 como um "ano de transição", pois a "tarefa de crescer" tornarase "muito mais árdua", embora considerasse "desastroso" adotar medidas que moderassem o ritmo econômico em um país que ainda estaria "construindo seu empresariado e sua estrutura industrial" ( $P \& D$, ago. 1974, p. 6-9).

O tema seria mais explicitamente tratado em $P \& D$ ao final do ano, quando Reis Velloso afirmou que "o mundo mudou, a partir de fins do ano passado", daí a necessidade de adaptarse "à realidade de escassez do petróleo, de preço quadruplicado" (P\&D, out. 1974, p. 10). Mas, as "razões para não perder o sono" estariam na própria história brasileira, pois "em duas épocas de aguda crise" o Brasil teria realizado "dois significativos surtos de industrialização: a época da Depressão dos anos 30 e o imediato pós-guerra”. Nesta avaliação histórica parece estar implícita uma aceitação das políticas que abriram o ciclo de substituição de importações. Defendia, à luz do passado, que fossem tomadas medidas para "não importar recessão" ( $P \& D$, nov. 1974, p. 42). A partir de então, e até o final da década, o tema da crise internacional não deixaria de ser abordado 
em $P \& D$, junto a questões como a concentração de renda, os baixos salários e o "nível de pobreza absoluta" da população rural ( $P \& D$, abr. 1976, p. 26).

O regime tratou de manter o nível de crescimento, numa atitude de "fugir para a frente", utilizando amplamente recursos do Estado para manter a economia aquecida (Prado e Earp, 2003, p. 234-235). Essa atuação gerou dissensos, então marcadamente influenciados pela grande imprensa, àquela altura em desacordo com a manutenção de expedientes autoritários, como a censura prévia, bem como paulatinamente favorável às críticas à intervenção do Estado, no que acompanhava o movimento do que seria mais tarde considerada uma "virada neoliberal" - apesar da imprecisão do termo - vislumbrada no horizonte internacional. Tanto as chamadas posições neokeynesianas quanto as defendidas na América Latina pela CEPAL passaram a sofrer a forte e articulada crítica por parte dos organismos financeiros internacionais, liderados pelo Fundo Monetário Internacional (FMI), e por entidades a estes vinculadas. Com grande visibilidade e defensores em posições-chave no chamado "mercado" ou nos governos, essa "contrarrevolução monetarista" - em oposição à chamada revolução keynesiana do início do século XX - preconizava um retorno à ortodoxia e aos primados liberais neoclássicos (Villarreal, 1983, p. 448-453).

Sob o comando de Geisel e na condição de ministro-chefe da SEPLAN, João Paulo dos Reis Velloso tornouse um dos principais dirigentes do regime, juntamente com o chefe do Serviço Nacional de Informações (SNI), João Figueiredo, o ministrochefe da Casa Militar, Hugo Abreu, e o ministrochefe da Casa Civil, Golbery do Couto e Silva (Abreu, 1979, p. 168). O planejamento das atividades econômicas tornarase peça central, articulado aos aparatos militares de controle social e de informações. Nessas áreas do governo tentavase impor o princípio da "legitimação pela eficácia”, identificado por Roberto Campos como base da estabilidade do regime, assegurando o "sucesso desenvolvimentista", o que compensaria as restrições à "participação popular" (Campos, 1976, p. 227). Reis Velloso acentuava que o país estaria "realizando seus objetivos econômicos e sociais", ao "realizar o desenvolvimento e a grandeza nacionais, sem descaracterização da experiência tropical-humanista da cultura brasileira" ( $P \& D$, jul. 1973, p. 9-10).

Nisso sua posição parecia contrastar com as vozes provenientes de um amplo espectro de intelectuais e economistas liberais também comprometidos com a ditadura. Em resposta direta ao economista Eugênio Gudin, que proferira uma dura avaliação sobre o governo no discurso em que recebeu um tradicional prêmio da revista Visão, em 1974, foi reproduzida uma conferência de Reis Velloso na qual se defendeu da acusação de que estaria sendo promovida uma “abrangente estatização da economia nacional”. Segundo Gudin, o capitalismo brasileiro só não seria mais estatizado do que a economia dos países comunistas. Velloso contestou tais apreciações 
ao defender que a "revolução" promovera "a aliança, a solidariedade, a informalidade de convívio entre governo e setor privado". Para ilustrar seu argumento, citou o filme Chinatown, de Roman Polanski, que mostrava uma cidade dos Estados Unidos numa época em que o abastecimento de água era controlado por empresas privadas: "é fácil imaginar as consequências econômicas, sociais e políticas, para tal sociedade, de uma dependência como essa". Destacava que sequer teria ocorrido o "milagre brasileiro" caso a "revolução" e seus governantes "se houvessem encantado pelo modelo capitalista vigente nos Estados Unidos", pois os investimentos em infraestrutura necessários ao país só foram viabilizados pela ação estatal. Entendia que desde 1964 o governo nada mais fazia do que "viabilizar o capitalismo (ou, se preferirem, o modelo de mercado) brasileiro" (P\&D, out. 1974, p. 10). De certo modo, a contenda ecoava questões que também motivaram Gudin a debater pioneiramente, ao fim do Estado Novo, entre 1944 e 1945, com o industrial Roberto Simonsen (Teixeira et al, 2010, p. 101-129).

Do ponto de vista político mais imediato, a crítica ao aparato estatal centralizado tendeu, durante aqueles anos da década de 1970 e a vigência do II PND, a acentuar a convergência dos setores oposicionistas, aproximando liberais a uma parte dos ativistas mais críticos e mesmo de setores à esquerda. Tornavamse frequentes as apreciações que rejeitavam a chamada tradição autoritária brasileira e os privilégios no setor público. Parcela significativa da grande imprensa passou a associarse a valores sociais vinculados aos direitos civis e a questionar o papel do Estado brasileiro. No interior das próprias bases governistas foram ouvidas vozes que criticavam a estatização, como os setores empresariais organizados pela Federação das Indústrias do Estado de São Paulo (FIESP), principalmente a partir de 1976. Embora recebesse apoio dos defensores de medidas derivadas do liberalismo econômico e de críticos do nacionalismo, o regime autoritário não desmontara parte dos mecanismos de intervenção do Estado na economia $e$ os objetivos desenvolvimentistas de industrializar o país por meio da ação coordenada governamental. As críticas ao "intervencionismo estatal" insuflaram uma "campanha contra a estatização", à qual se engajou a "imprensa liberalconservadora e amplos setores do empresariado brasileiro" (Cruz e Moraes, 2008, p. 10-11). Retomavam certas posições do liberalismo brasileiro ao fim da Segunda Guerra Mundial, além de, como na ocasião, não tardar a demandar que o aparelho repressivo fosse ainda mais eficaz contra o movimento sindical em ascensão (Bianchi, 2001, p. 128).

De sua parte, Reis Velloso utilizou $P \& D$ para responder aos críticos, reproduzindo textos publicados na grande imprensa. Numa dessas oportunidades, enfatizou que o governo tinha "a opção básica pelo regime de mercado, aceitando, inclusive, que lucro não é pecado", contudo situava "a empresa privada como agente da sociedade". Como a "economia de mercado não vive 
de boas intenções", o setor privado deveria submeterse às metas de crescimento governamentais e a "incorporação do capital externo à estratégia nacional". A empresa privada nacional dependeria de mecanismos de obtenção de capitais que estavam sendo abertas pelo Banco Nacional de Desenvolvimento Econômico (então BNDE, hoje BNDES), frisando que tal participação não significaria "controle acionário", ou seja, estatização ( $P \& D$, jul. 1974, p. 8-9).

Manifestações diversas preconizavam maior diálogo entre governo e classes empresariais, ampliando a "democracia restrita" e questionando a "centralização do crédito público e o controle, pelo Estado, da quase totalidade dos investimentos produtivos" (Codato, 1995, p. 75). A grande imprensa dava voz aos descontentamentos dos setores mais próximos ao regime. Em uma série de reportagens, entre fevereiro e março de 1975, o jornal O Estado de São Paulo denunciou o que intitulou de "os caminhos da estatização". A primeira matéria chamou a atenção para a preocupação entre empresários paulistas, mantidos "num cauteloso anonimato", em relação à "estatização de vários setores da economia", particularmente no setor financeiro, por meio do BNDE. O sigilo das queixas seria um forte indício da "situação de dependência em que vivem esses empresários". Com base em levantamento de Eugênio Gudin, Octávio Gouvêa de Bulhões, Affonso Celso Pastore e Carlos Langoni, o jornal informava que impostos e tarifas consumiam "mais de 4\% da poupança do país". Diante disso, questionava a reportagem: "como haver disponibilidade financeira para movimentar o mercado de ações, como dinamizar a Bolsa ou investir diretamente?". Para Gudin, o BNDE era um "verdadeiro Leviatã a absorver as empresas". Contra o argumento de que o governo defendia as empresas privadas do risco de desnacionalização, os interlocutores do jornal rebatiam que bastaria apoiar o "mercado de ações" por meio de "crédito mais fácil e menos caro", de modo a favorecer uma "livre economia de mercado", sem que o Estado absorvesse "áreas rentáveis". Empresários demandavam exercer maior influência e viam-se bloqueados por "uma verdadeira elite de burocratas cada vez mais especializados". Em conclusão: "parece que o governo hoje está sendo por demais influenciado pelos burocratas". ${ }^{4}$ Por isso, seria indispensável a reação da iniciativa privada, por meio de entidades de classe, contra os "tecnocratas do governo". ${ }^{5}$ Estavam em jogo disputas surdas entre os que se sentiam prejudicados por posições julgadas nacionalistas em excesso e os que se viam discriminados em relação ao setor de bens de capital. Nessas fissuras, lideranças políticas da oposição ganhavam prestígio e influência, bem como colaboradores do regime trocaram de lado, como o ministro da Indústria e Comércio, o empresário Severo Gomes.

No ano seguinte, sob a condução do próprio Reis Velloso, $P \& D$ publicou o documento intitulado "O governo e a economia de mercado", que buscava sugestões junto ao empresariado 
para ampliar sua participação no "desenvolvimento nacional". Era uma nítida resposta a "algumas correntes radicais" que teriam procurado "conduzir o assunto a posições extremadas". Contra os críticos, o governo insistia em manter a implantação e as metas estabelecidas no II PND, as quais envolviam a previsão de elevado nível de investimentos públicos. O documento era taxativo: "o governo pensa e vai fazer o que está no II PND, aprovado pelo Congresso Nacional", procurando demonstrar que este assegurava os espaços necessários ao capital privado. E mantinha a postura de afirmar que "nenhum governo, como o atual, deu tantas e tão amplas provas de ser fiel ao propósito de fazer funcionar no Brasil uma economia de mercado" ( $P \& D$, jul. 1976, p. 5-8).

Portanto, as discussões sobre a pretensa estatização da economia, durante o governo de Geisel, envolviam tensões fundamentais no interior do regime. Controle estatal e AI-5 apareciam nessas narrativas como elementos interrelacionados. No interior do núcleo responsável pela economia o tema gerou dissensões. Significativos foram os conflitos entre Reis Velloso e o ministro da Fazenda, Mário Henrique Simonsen. Responsável pela formulação e implantação dos planos de desenvolvimento, Reis Velloso, juntamente com Severo Gomes, propugnava investimentos públicos em favor do capital nacional, com pressões inflacionárias, ao que reagia a área da Fazenda e o Banco Central. Este jogo de forças entre posições desenvolvimentistas e monetaristas indicava que "a burocracia do Ministério da Fazenda era 'mais representativa do empresariado', enquanto a burocracia da Secretaria de Planejamento expressaria melhor os interesses ou o projeto de 'intervenção' do Estado" (Codato, 1994, p. 73). Tais fissuras no centro do regime não deixaram de ser exploradas pela oposição no Congresso que, apesar das limitações, a partir da vitória eleitoral de 1974, passou a utilizar de alguns instrumentos para forçar o governo a pronunciarse sobre temas como a política salarial e as multinacionais. A revista $P \& D$ publicou na época um longo estudo técnico que ressaltava a importância das empresas estrangeiras para o desenvolvimento tecnológico do país, numa tentativa de responder à oposição $(P \& D$, dez. 1975 , p. 12).

Na narrativa que passou a predominar na grande imprensa, Estado e sociedade civil foram descritos como elementos antitéticos no conjunto das frágeis condições de institucionalização política do país. Dali em diante, especialmente na década seguinte, esteve em jogo "a consolidação da hegemonia liberal no processo imediato de transição" (Napolitano, 2002, p. 154-158). A crise da ditadura passava a ser vista, entre interlocutores dos dois lados do jogo político, como oportunidade para a implantação de um novo padrão de organização do Estado em que a democracia seria instrumental para a liberdade de movimentos do mercado financeiro. 
A construção de uma hegemonia liberal na forma de pensar as questões nacionais fazia com que patrimonialismo e estatismo aparecessem como dimensões do mesmo problema: a ditadura então vigente e o autoritarismo das relações de poder. A crise da ditadura era tomada como parte do colapso de um modelo político e econômico arcaico que promovera o desenvolvimento à custa da manutenção de uma sociedade refratária à modernidade capitalista. Introduzia-se a questão de que os problemas brasileiros estavam ligados à falência do desenvolvimentismo estatista e ainda à ausência de liberdade, não só política, mas também econômica, um indício de "atraso". A redemocratização aparecia, então, como superação não apenas de uma ditadura militar, mas de uma mentalidade nacional impregnada de estatismo, autoritarismo e maus hábitos políticos, quase todos incrustrados na administração pública, dominada por corrupção, ineficiência e patrimonialismo.

Naquele momento, entre os críticos do regime, destacouse o jurista Raymundo Faoro, autor do clássico Os donos do poder, publicado originalmente em 1958 e reeditado em 1973, o qual reivindicou a influência de Max Weber e deslocou a análise histórica da sociedade brasileira para o Estado, pontificando que no Brasil "a camada dirigente atua em nome próprio servida dos instrumentos de sua posse do aparelhamento estatal", seja pela "gestão direta" ou pela "regulamentação material da economia" (Faoro, 2001, p. 824-834). Para Jessé Souza, essa acepção conduzia a compreender que o desenvolvimento capitalista brasileiro teria tomado uma forma ibérica, prescindindo de "separação precisa entre as esferas econômica e política da sociedade", o que, dessa forma, reduziria a conquista do poder "à lógica do controle direto de uma fonte substancial de riqueza em si: o próprio aparelho estatal" (Souza, 1998, p. 108). O foco da crítica passava a ser um Estado sequestrado pelo personalismo que resultava em um sistema social patrimonialista. Essas considerações sobre a sociedade brasileira caíam então em terreno fértil, quando a um Estado tomado como essencialmente autoritário e corrupto passaram a ser atribuídas as razões para a existência de uma ditadura. A elite gerencial e burocrática, beneficiária do regime, não teria dificuldades em se adaptar a esta narrativa.

Reis Velloso avaliaria todo o período iniciado com o golpe de 1964 como uma "evolução do patrimonialismo brasileiro" em direção a uma organização weberiana. De certo modo, o debate internacional e as questões que dele eram extraídas para as discussões sobre a construção de um regime democrático no Brasil propunham uma preocupação renovada com a política e a economia, atreladas a uma estrutura de poder que se apresentava tradicional e refratária à livre iniciativa, pelo menos numa interpretação liberal (Castro e D’Araújo, 2004, p. 82-83; 101). No interior do próprio governo atuavam economistas ligados à oposição, como Edmar Bacha e Pedro 
Malan, vinculados ao IPEA, que se tornariam mais tarde formuladores de reformas do setor público orientadas para a redução dos robustos instrumentos coordenadores e intervencionistas estatais. Ou seja, o que antes eram imprecações de economistas profundamente comprometidos com a própria ditadura e com as forças conservadoras no Brasil, ganhava amplitude intelectual na forma de uma crítica abrangente à sociedade brasileira, vista como impermeável à democracia e o livre mercado.

\section{Sem planejamento e sem desenvolvimento, mas com comando}

No ano de 1977, o próprio Reis Velloso visitou a FIESP, numa postura que mais pareceu de capitulação aos que exigiam medidas de austeridade fiscal. Em seu pronunciamento, embora celebrasse o êxito em evitar a adoção de medidas recessivas, reconheceu que "realmente, é chegado o momento de concentrar esforços na contenção da inflação e na redução do déficit na balança de pagamentos", desacelerando a economia e os investimentos (P\&D, mar. 1977, p. 89). Preparandose para os impactos políticos das medidas, com o crescente apoio popular à oposição, o governo lançaria em abril daquele ano uma série de medidas que alteraram dispositivos constitucionais e impuseram o fechamento temporário do Congresso. $\mathrm{O}$ "pacote de abril de 1977" visava garantir que o partido governista não viesse a sofrer maiores reveses nas eleições previstas para o ano seguinte. A nova conjuntura política permitiu ao ministro fazer um giro em que, de acusado de promotor da estatização, passou a ser ele próprio um defensor da iniciativa privada, contrariamente aos oposicionistas, entre os quais havia os que propugnavam um tipo de intervenção estatal considerado um "modelo econômico radical". Parte da oposição acusava o governo de promover a desnacionalização da economia (Castro e D’Araújo, 2004, p. 182) e propunha medidas como a estatização do setor financeiro, restrições às importações $e$ elevações salariais. Segundo Velloso, tais propostas projetariam uma "proletarização de toda a sociedade" e um país "culturalmente fechado". Contra o que seria uma tutela do Estado, defendia que a "dimensão social da liberdade deve ser a mais ampla possível" ( $P \& D$, ago. 1977, p. 8-11), numa fala que apontava para a conciliação que presidiria o processo de redemocratização.

Dois anos depois, de saída do Ministério, Reis Velloso procurou fazer um balanço positivo do II PND. Este, em suas palavras, teria objetivado a consolidação no país de um "modelo neocapitalista", de modo a evitar "os perigos da desnacionalização e da estatização", ao passo em que atentava para o "problema da distribuição de renda" ( $P \& D$, fev. 1979 , p. 9). O termo neocapitalismo encontrou diversos empregos entre os anos de 1960 e 1970, podendo vincularse 
a diferentes concepções (Weber, 1994; Galbraith, 1977; Myrdal, 1963), mas também a perspectivas críticas acerca de tal abordagem (Mills, 1975; Mandel, 1971; Habermas, 1980; Gorz, 1968). É possível compreender que, em linhas gerais, o neocapitalismo defendido por Velloso dizia respeito ao que seria a forma de capitalismo das sociedades altamente industrializadas, baseado em grandes empresas monopolistas e no qual o Estado atuaria por meio de uma burocracia tecnicamente preparada, na forma de administradores e gerentes (Covre, 1980, p. 4449).

A análise desses episódios conflitivos permite relativizar algumas interpretações que acentuaram a abrangência da burocratização dos regimes autoritários latinoamericanos da década de 1970, característica que afetaria seus "eixos de poder", incluindo os próprios militares, que estariam também submetidos a uma ordem "tecnoburocrática", tomada como um polo de poder político quase autônomo no interior do aparato do Estado autoritário (O’Donnel, 1990; Cardoso, 1975; Martins, 1974; Pereira, 1978). Tais posicionamentos teóricos anteciparam certos aspectos do debate atual em torno da condição militar ou civilmilitar da ditadura, embora obviamente sem esta intenção. Ao associarem ditadura e poder tecnoburocrático, indicavam que tanto militares quanto civis integrantes dos estratos superiores da burocracia assumiam condições simétricas. Ciente de que esta discussão está em pleno andamento, com posicionamentos consistentes a partir de abordagens e fundos documentais diversos, cabe situar-se com cautela neste debate, que tem sido focalizado sob perspectivas diversas (Pagliarini, 2017), sem pretender de maneira alguma sugerir uma conclusão.

A percepção das discussões ocorridas no interior do regime, conhecidas a partir de suas próprias expressões públicas, como é o caso da revista $P \& D$, indica a prevalência do "caráter ditatorialmilitar" do regime. Como aponta João Roberto Martins Filho, os militares não abriram mão da tarefa de distinguir-se do "mundo civil" e de oporse ao "mundo político", identificado com o "populismo", eivado dos defeitos nacionais que teriam levado à necessidade da imposição do regime (Martins Filho, 1994, p. 15-19). Suzeley Kalil Mathias sugere que, se de um lado a militarização da burocracia não foi tão extensa quanto se poderia pensar à primeira vista, mostrouse eficaz no sentido de manter sob controle centralizado dos militares o comando estratégico, de unidade e de integração territorial, mesmo quando estes lançavam mão de práticas tradicionais e clientelistas no relacionamento com o poder político, organizando as demandas e os interesses de classe por meio de órgãos de assessoria e planejamento. Dessa forma, "os interesses particulares transformavam-se em políticas públicas, anulando, assim, o papel que deveria ser exercido tanto pela estrutura burocrática formal quanto pelo Legislativo" (Mathias, 2004, p. 201). 
Há aí uma indicação da existência de tensões que influenciariam tomadas de posição ao longo dos anos da abertura, quando começaram a surgir denúncias de desvios administrativos.

Para Martins Filho, ao abordar os dois primeiros governos da ditatura, as análises que acentuam a prevalência da lógica burocrática na estrutura do regime superestimaram os discursos e projetos abrangentes então anunciados, reduzindo a importância dos elementos propriamente militares (Martins Filho, 1995, p. 21). Assim, a especificidade do Estado autoritário imposto pela ditadura estaria menos na burocratização e mais na própria militarização do Estado e na defesa da unidade das Forças Armadas acima de quaisquer fissuras advindas das áreas de influência civil, sendo que as crises surgidas tinham a ver com as tensões quanto à forma de atuação políticomilitar e a pluralidade de posições acerca deste tema. Pode-se sugerir que tais elementos não tornavam os militares um polo homogêneo que, em conjunto com os civis, tivessem um plano único de alguma forma pressuposto numa denominação como "civil-militar", justamente porque a unidade é obtida pelos militares não em conjunto com os civis, mas em pretensa contraposição ao mundo dos políticos e da política. Se havia influência considerável de uma burocracia civil, esta não deixou de subordinar-se, juntamente com as bases sociais do regime, em particular os setores do empresariado industrial e os elementos político-partidários, aos ritmos impostos pelos militares e suas disputas internas. Reis Velloso lembrou que no caso das disputas entre as áreas da Fazenda e do Planejamento, Geisel teve a última palavra, ao afirmar que "a posição oficial do governo estava definida" em favor de não discriminar o capital estrangeiro (Velloso, 1998, p. 20). O poder militar palaciano destacavase e definia o resultado de quaisquer disputas no interior da burocracia. O general-presidente impunha ainda que não houvesse "'brigalhada' de ministros pela imprensa", pois não admitia ser "presidente de bagunça” (Castro e D’Araújo, 2004, p. 179).

Coube ao elemento castrense a palavra final $e$ a afirmação definitiva do poder do presidentemilitar e seu núcleo palaciano, quando Geisel tratou de impor-se a todas as frações de poder para determinar tanto a política econômica quanto um sucessor contestado (Skidmore, 1988, p. 46-49). Dessa forma, quanto ao particular debate acerca da condição da ditadura, é possível apontar, conforme Carlos Fico, que o regime foi "controlado pelos militares" (Fico, 2017, p. 54-56), em um amplo balanço das posições assumidas sobre este tema por diferentes historiadores. Para o autor, o Poder Executivo teve "plenos poderes" desde os primeiros Atos Institucionais e ao longo da vigência do regime, e não apenas sob as condições impostas pelo AI5 , cabendo aos militares definir o planejamento e a execução do aparato repressivo quanto às estratégias de desenvolvimento. 
Em 1979, sob a batuta de um novo general em seu comando, a ditadura implementou mudanças na Secretaria de Planejamento da Presidência da República, passando por Mário Henrique Simonsen e Golbery do Couto e Silva, até a nomeação de Delfim Netto. Em resposta à imposição do nome do general João Figueiredo como sucessor de Geisel, militares até então muito influentes, e inclusive identificados com a chamada "linha dura", passaram a dialogar com frequência com a oposição, como foi o caso de Hugo Abreu, que ao romper com o regime lançou mão de uma prédica nacionalista e o desvirtuamento dos "ideais revolucionários", a desnacionalização da economia, além da corrupção e o envolvimento direto de figuras como Golbery com multinacionais (Abreu, 1979, p. 168). Manifestos de oficiais denunciavam a transformação dos militares em "guarda pretoriana" e demandavam o "restabelecimento pleno da democracia" e a "convocação de uma Assembleia Nacional Constituinte". ‘

Entre setores de oposição e situação estabelecia-se um tipo de leitura da realidade em que a superação da ditadura significaria liberdade, não apenas como expressão de abertura política, mas de ampliação do espaço para a iniciativa privada no contexto de uma economia de mercado. Ao longo do governo Figueiredo, os novos comandantes do regime anunciavam ser uma "consequência natural da abertura política" que houvesse "a diminuição do coeficiente de tutela do Estado sobre a sociedade" ( $P \& D$, abr. 1979, p. 9). Na primeira vez em que a revista $P \& D$ reproduziu uma entrevista do ministro Delfim Netto, ao ser questionado sobre sua atuação nos governos militares, reafirmou sua anuência ao AI-5: "assinaria de novo se as condições fossem as mesmas". Entendia, contudo, que chegara o momento da abertura e seria necessário evitar "fechar tudo de novo e baixar o porrete". Daí que "o grande objetivo de toda a estratégia montada na área econômica" fosse a "manutenção do sistema politicamente aberto" (P\&D, out. 1979, p. 2940).

O ministro buscava estar em sintonia com os segmentos empresariais mais poderosos do país que, entre 1977 e 1978, haviam formalizado documentos coletivos com grande impacto na imprensa em que defendiam a combinação da economia de mercado com um novo sistema político. Em duas ocasiões, na chamada "Carta do Rio de Janeiro" e no "Documento dos Oito", o empresariado posicionou-se contra a centralização dos mecanismos de crédito e de planejamento, bem como por novas relações políticas. Os empresários autores destes documentos, a partir de diferentes pontos de vista e compromissos com as forças políticas em disputa, alinhavam-se às tendências dos agentes econômicos internacionais, que passavam a pleitear a desregulamentação do mercado financeiro e do sistema de crédito, ao mesmo tempo em que

\footnotetext{
† Conforme a matéria “As dissidências militares”, publicada em Movimento (São Paulo, 07/08/1978, p. 4).
} 
defendiam que se abrissem espaços institucionais para participarem das decisões governamentais (Codato, 1995, p. 79-85). Algumas dessas lideranças aproximaram-se dos oposicionistas liberais e teriam importância destacada nos resultados eleitorais das duas décadas seguintes.

Depois do fim do longo predomínio de Reis Velloso, a equipe de produção da revista $P \& D$ também teve rápidas mudanças de comando. Entre os encarregados pela publicação ao longo de 1979 até 1984, figuraram nomes tais como Waldimir Diniz, jornalista que trabalhara na Rede Globo e na revista Veja; Sebastião Marcos Vital, economista que fora redator da revista Conjuntura Econômica; a jornalista Noriko Ohta, com passagens por O Globo e Jornal do Brasil; Henrique Galinkin, jornalista e funcionário da Receita Federal; Luiz Ribeiro de Mendonça, jornalista e funcionário de carreira; e José Bernardes, jornalista com passagem pelo jornal Correio Braziliense. A partir de 1980, a revista perdeu importância no âmbito das estratégias de comunicação da SEPLAN e reduziu o número edições. Entre 1980 e 1983, foram publicados apenas dois números por ano, até que vieram a público suas últimas três edições em 1984.

O último número da revista é o de dezembro daquele ano, às vésperas da votação no Colégio Eleitoral que elegeria Tancredo Neves e José Sarney, conforme os acordos para a transferência do poder para um governo civil. É significativo que a última matéria de capa tenha sido dedicada à reforma agrária, tema que voltava ao debate público depois de haver preenchido os debates e alcançado aprovação popular no contexto do golpe de 1964 (Motta, 2014, p. 7). A revista destacava que em 20 anos o regime autoritário teria sido responsável por distribuir cerca de um milhão de títulos de terra, sendo 200 mil no governo Figueiredo. Tudo teria sido feito "sem alardes e de forma cuidadosa, para não ferir a iniciativa privada, a justiça social e a harmonia entre as categorias sociais da produção". A ditadura celebrava que, desde a implantação do Estatuto da Terra, o país recebera o "maior programa de colonização já realizado no continente americano" (P\&D, dez. 1984, p. 49-60). O regime reverberava números altissonantes de um ideário que então encontrava inúmeras dificuldades para angariar legitimidade, dado que não encontrava mais respaldo naqueles que apenas alguns anos antes beneficiaramse das medidas governamentais. Os críticos do planejamento centralizado ganhavam espaço $e$ influência, processo que teria continuidade nos governos civis que se seguiram, sob uma hegemonia liberal que, ao mesmo tempo em que atacava os instrumentos de intervenção estatal na economia, não se daria à tarefa de desmontar parte das estruturas burocráticas e autoritárias que limitam o processo democrático brasileiro.

\section{Referências}


ABREU, Hugo. O outro lado do poder. Rio de Janeiro: Nova Fronteira, 1979.

BIANCHI, Alvaro. Crise e representação empresarial: o surgimento do pensamento nacional das bases empresariais. Revista de Sociologia e Política, Curitiba, n. 16, jun., 2001, p. 123-142.

CAMPOS, Roberto de Oliveira. A opção política brasileira. In: SIMONSEN, Mário Henrique; CAMPOS, Roberto de Oliveira. A nova economia brasileira. Rio de Janeiro: J. Olympio, 1976, p. 223-257.

CAPELATO, Maria Helena Rolim. Multidões em cena: propaganda politica no varguismo e no peronismo. Papirus: Campinas, 1998.

CARDOSO, Fernando Henrique. Autoritarismo e democratização. Rio de Janeiro: Paz e Terra, 1975.

CARVALHO, José Murilo de. Vargas e os militares, aprendiz de feiticeiro. In: D’ARAÚJO, Maria Celina de. As instituiçôes brasileiras da era Vargas. Rio de Janeiro: EDUERJ/FGV, 1999, p. 55-82.

CASTRO, Celso \& D'ARAÚJO, Maria Celina de. Tempos modernos. João Paulo dos Reis Velloso: memórias do desenvolvimento. Rio de Janeiro: FGV, 2004.

CODATO, Adriano Nervo. A burguesia contra o Estado? Crise política, ação de classe e os rumos da transição. Revista de Sociologia e Politica, Curitiba, n.4/5, 1995, p. 55-87.

CODATO, Adriano Nervo. Centralização política e processo decisório: o governo Geisel em perspectiva. Revista de Sociologia e Política, Curitiba, n. 2, 1994, p. 57-78.

CORDEIRO, Janaína Martins. Anos de chumbo ou anos de ouro? A memória social sobre o governo Médici. Estudos Históricos, Rio de Janeiro, v. 22, n. 43, jan./jun., 2009, p. 85-104.

COVRE, Maria de Lourdes Manzini. Uma discussão teórica: ideologia neocapitalista e processo de burocratização. Revista de Administração de Empresas, São Paulo, v.20, n.1, jan./mar., 1980, p. 4361.

CRUZ, Sebastião Velasco; MORAES, Reginaldo Corrêa. A Construção Retomada. Desafios Políticos e Perspectivas Internacionais para o Brasil. In: Nueva Sociedad Português, Buenos Aires, out. 2008. Acesso on line: http://nuso.org/media/articles/downloads/p9-1_1.pdf

DREIFUSS, René Armand. 1964: a conquista do Estado - ação politica, poder e golpe de classe. Petrópolis: Vozes, 1981. 
FAORO, Raymundo. Os donos do poder: formaçẫo do patronato politico brasileiro. 3. ed. São Paulo: Globo, 2001.

FICO, Carlos. Ditadura militar brasileira: aproximações teóricas e historiográficas. Tempo e Argumento, Florianópolis, v.9, n. 20, jan./abr., 2017, p. 5-74.

FICO, Carlos. Reinventando o otimismo: ditadura, propaganda e imaginário social no Brasii. Rio de Janeiro: Editora FGV, 1997.

FIORIN, José Luiz. O regime de 1964: discurso e ideologia. São Paulo: Atual, 1988.

GALBRAITH, John Kenneth. O novo estado industriai. São Paulo: Pioneira, 1977.

GOMES, Angela de Castro. História e historiadores. Rio de Janeiro: FGV, 1996.

GORZ, André. Estratégia operária e neocapitalismo. Rio de Janeiro: Zahar, 1968.

HABERMAS, Jürgen. A crise de legitimação no capitalismo tardio. Rio de Janeiro: Tempo Brasileiro, 1980.

LUNA, Francisco Vidal; KLEIN, Herbert. Mudanças sociais no período militar (1964-1985). In: REIS, Daniel Aarão; RIDENTI; Marcelo; MOTTA, Rodrigo Patto Sá (orgs.). A ditadura que mudou o Brasil: 50 anos do golpe de 1964. Rio de Janeiro: Zahar, 2014, p. 66-91.

MANDEL, Ernest. Ensayos sobre el neocapitalismo. Ciudad de México: Era, 1971.

MARTINS Filho, João Roberto. Estado e regime no pós-64: autoritarismo burocrático ou ditadura militar? Revista de Sociologia e Politica, Curitiba, n.2, 1994, p. 7-23.

MARTINS Filho, João Roberto. O palácio e a caserna: a dinâmica militar das crises políticas na ditadura (19641969). São Carlos: Editora da UFSCar, 1995.

MARTINS, Carlos Estevam. Tecnocracia e capitalismo: a política dos técnicos no Brasil. São Paulo: Brasiliense, 1974.

MATHIAS, Suzely Kalil. A militarização da burocracia: a participação militar na administração federal das comunicações e da educação. São Paulo: UNESP, 2004. 
MELLO, João Manuel Cardoso de. A contra-revolução liberal-conservadora e a tradição crítica latino-americana. Um prólogo em homenagem a Celso Furtado. Economia e Sociedade, Campinas, v. 6, n. 2, dez. 1997, p. 159-164.

MILLS, Wright. A nova classe média. Rio de Janeiro: Zahar, 1979.

MILLS, Wright. A elite do poder. Rio de Janeiro: Zahar, 1975.

MOTTA, Rodrigo Patto Sá. O golpe de 1964 e a ditadura nas pesquisas de opinião. Tempo, Niterói, v. 20, n. 36, jan./dez. 2014, p. 1-21.

MYRDAL, Gunnar. Planifier pour developper: de l'etat-previdence au monde-providence. Paris: Ed. Ouvrières, 1963.

NAPOLITANO, Marcos. Cultura e poder no Brasil contemporânec. Curitiba: Juruá, 2002.

O’DONNELL, Guillermo. Análise do autoritarismo burocrático. Rio de Janeiro: Paz e Terra, 1990.

OFFE, Claus. Problemas estruturais do Estado capitalista. Rio de Janeiro: Tempo Brasileiro, 1984.

P\&D: Planejamento e Desenvolvimento. Brasília: SEPLAN, 1973-1984.

PAGLIARINI, André. De onde? Para onde? The Continuity Question and the Debate over Brazil's "Civil"Military Dictatorship. Latin American Research Review, Pittsburgh, v.52, n.5, 2017, p. 760-774. Disponível em: https://larrlasa.org/articles/10.25222/larr.216

PASTORE, José. Emprego, renda e mobilidade no Brasil. Pesquisa e Planejamento Econômico, v. 6, n. 3, dez. 1976, p. 551-586.

PEREIRA, Luiz Carlos Bresser. O colapso de uma aliança de classes. São Paulo: Brasiliense, 1978.

PRADO, Luiz Carlos Delorme; EARP, Fábio Sá. O "milagre" brasileiro: crescimento acelerado, integração nacional e concentração de renda. In: FERREIRA, Jorge; DELGADO, Lucília de Almeida Neves. O Brasil republicano, 4: $\mathrm{O}$ tempo da ditadura. Regime militar e movimentos sociais em fins do século XX. Rio de Janeiro: Civilização Brasileira: 2003, p. 207-242.

SCHNEIDER, Nina. Propaganda ditatorial e invasão do cotidiano: a ditadura militar em perspectiva comparada. Estudos Ibero-Americanos, Porto Alegre, v. 43, n. 2, 2017, p. 333-345. 
SILVA, Salomão Quadros da. O Brasil de Getúlio Vargas visto da Fundação Getúlio Vargas. In: GOMES, Angela de Castro. Vargas e a crise dos anos 50. Rio de Janeiro: RelumeDumará, 1994, p. 205-224.

SKIDMORE, Thomas E. A lenta via brasileira para a redemocratização: 1974-1985. In: STEPAN, Alfred. Democratizando o Brasil. Rio de Janeiro: Paz e Terra, 1988, p. 27-81.

SKIDMORE, Thomas E. The politics of military rule in Brazil, 1964-1985. New York: Oxford University Press, 1990.

SOUZA, Jessé. A ética protestante e a ideologia do atraso brasileiro. Revista Brasileira de Ciências Sociais, São Paulo, v.13, n.38, out. 1998, p. 97-116.

TEIXEIRA, Aloísio; MARINGONI, Gilberto; GENTIL, Denise Lobato. Desenvolvimento: o debate pioneiro de 19441945. Brasília: IPEA, 2010.

TRINDADE, Hélgio. Bases da democracia brasileira: lógica liberal e práxis autoritária (1822/1945). In: ROUQUIÉ, Alain; LAMOUNIER, Bolivar; SCHWARZER, Jorge (orgs.). Assim renascem as democracias. São Paulo: Brasiliense, 1985, p. 46-72.

VELLOSO, João Paulo dos Reis. O governo Geisel: estratégia de desenvolvimento e coordenação da política econômica. Revista Brasileira de Economia, Rio de Janeiro, v. 52, 1998, p. 15-26.

VILLARREAL, René. La contrarrevolución monetarista en el centro y la periferia. El Trimestre Económico, Ciudad de México, v. 50, n. 197, jan./mar., 1983, p. 429-471.

WEBER, Max. Economia e sociedade: fundamentos da sociologia compreensiva. Brasília: Ed. UnB, 1994, 2v.

\footnotetext{
${ }^{1}$ Denominação conforme o documento "Estratégia do IV governo da revolução", editado pelo IBGE em 1976.

${ }^{2}$ Conforme a matéria "Geisel repele pressões indevidas", publicada em Folha de São Paulo (São Paulo, 30/08/1974, p. 1).

${ }^{3}$ Conforme a matéria "Líbia anuncia aumento de $30 \%$ no barril de petróleo", publicada em Jornal do Brasil (Rio de Janeiro, 04/09/1973, p. 1).

${ }^{4}$ Conforme a matéria "Os caminhos da estatização - 1: No setor de crédito a nova investida estatal", publicada em $O$ Estado de São Paulo (São Paulo, 16/02/1975, p. 28).

${ }^{5}$ Conforme a matéria "Os caminhos da estatização - final: Engrenagem favorece o poder do Estado", publicada em $O$ Estado de São Paulo (São Paulo, 02/02/1975, p. 38).
} 